\title{
A Convergent Coupling Strategy for the Formation of Polycyclic Ethers: Stereoselective Synthesis of the BCDE fragment of Brevetoxin A
}

Michael T. Crimmins*, Patrick J. McDougall, Kyle A. Emmitte

Venable and Kenan Laboratories of Chemistry, University of North Carolina at Chapel Hill, Chapel Hill, North Carolina, 27599

crimmins@email.unc.edu

Supporting Information

NMR Spectral Data 


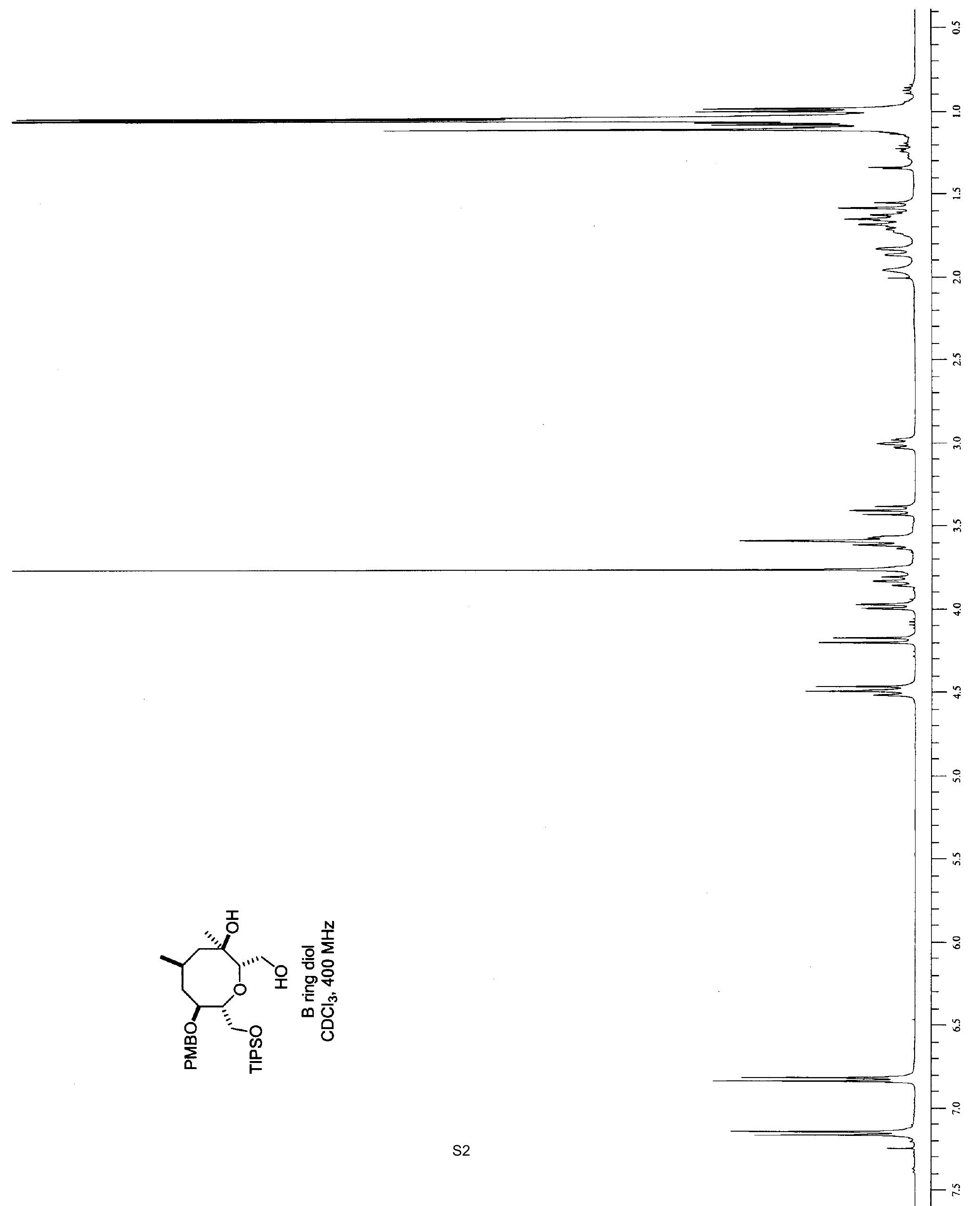





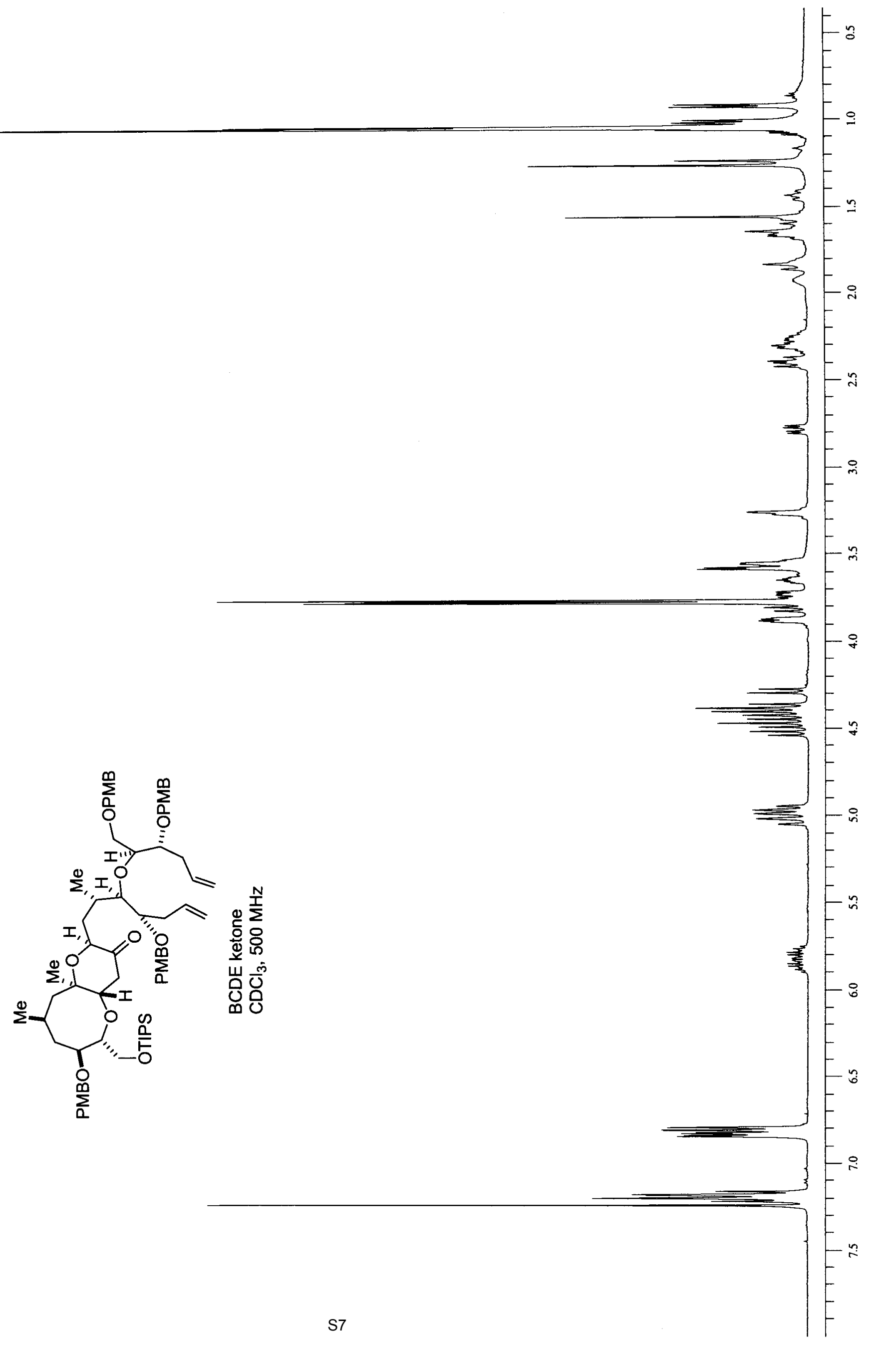




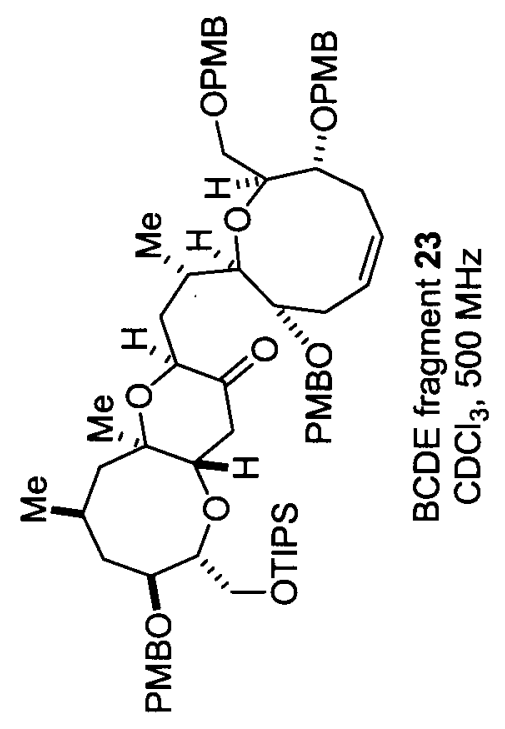




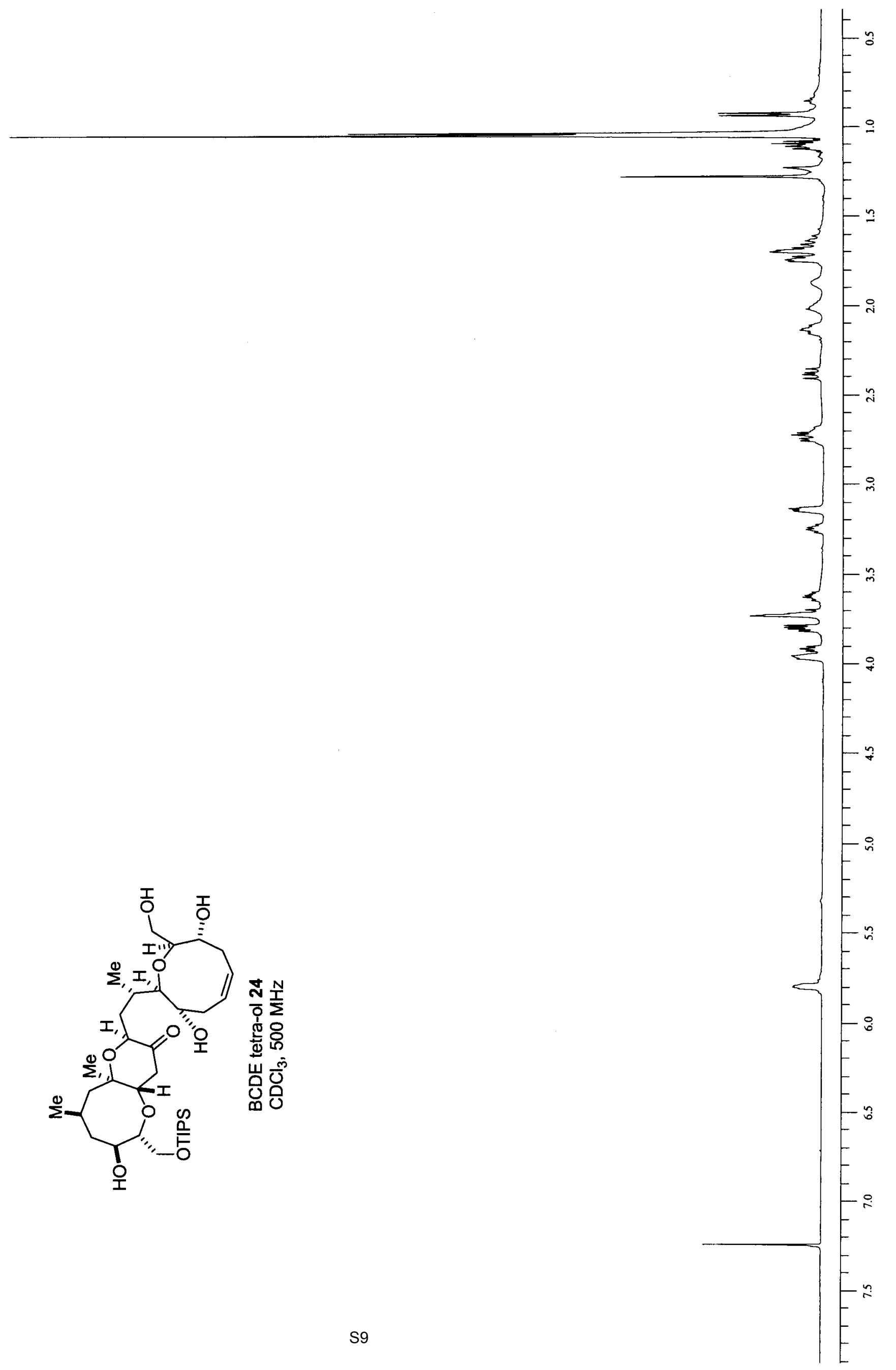




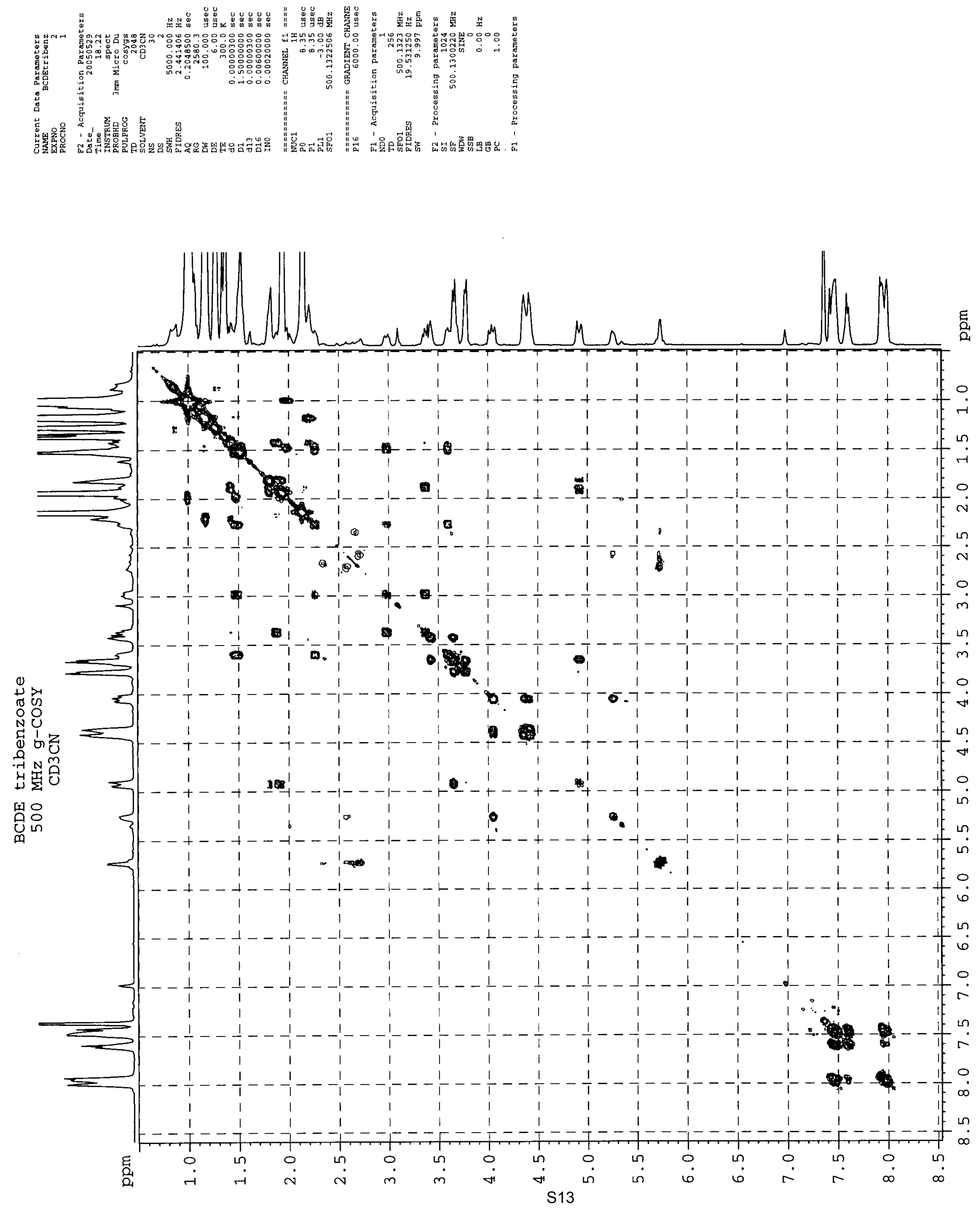


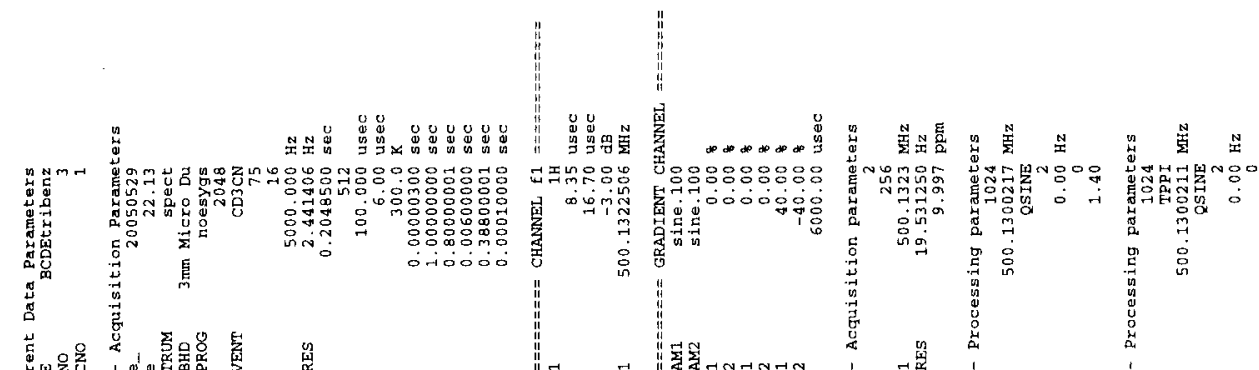

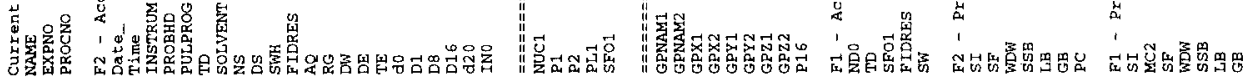

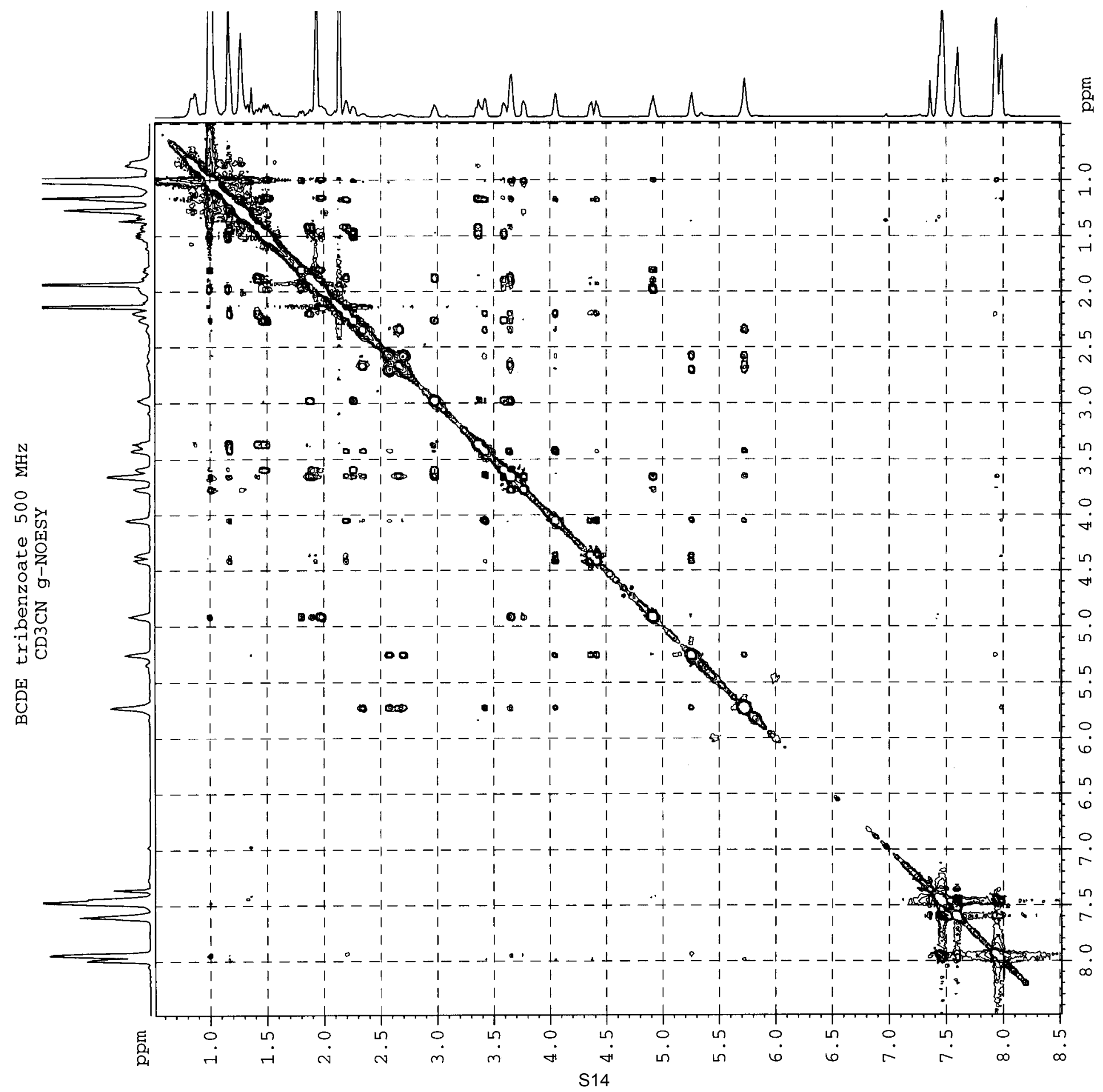

